\title{
Sentido y alcance de la justicia en Aristóteles ${ }^{1}$
}

\author{
Melissa Llauce Ontaneda \\ Universidad de Piura
}

En una sociedad donde prima el olvido del sentido de justicia, se echa en falta trabajos sobre este tema a nivel integral, es decir, cuando se habla de justicia no nos referimos solo a la justicia que toma forma en los tribunales o en nuestro sistema jurídico. La justicia es más que una expresión jurídica, la justicia como bien lo expresan los clásicos es una virtud necesaria para el hombre y primordial para su vida en comunidad.

No es mi objetivo presentar un trabajo sobre los problemas actuales de la justicia, sino más bien volver al estudio de la justicia desde un campo puramente conceptual, esto significa volver a una de las teorías más cimentadas. Este trabajo se centra en el tratamiento dado por Aristóteles, específicamente en el libro V de la Ética a Nicómaco.

Es innegable que la filosofía aristotélica ha sido, es y seguirá siendo trabajada desde el ámbito de la investigación universitaria. Es más, el tema que a continuación presento no es novedoso, pero sí crucial en el tratamiento ético del Estagirita pues para Aristóteles la justicia es una virtud, esto quiere decir que configura y repercute en el ser humano.

\section{Aspectos centrales de la justicia aristotélica}

En el libro V de la Ética a Nicómaco, Aristóteles se refiere a la justicia. En el texto aparecen específicamente los términos de justicia doméstica, justicia política, justicia natural y justicia legal. Puede parecer que, al hablar de justicia doméstica, es decir, lo que comprende la casa o la familia, nos referimos a lo natural; de la misma manera que, al decir justicia política podría pensarse que nos movemos en el ámbito de lo convencional o estrictamente legal, que configura un espacio de actuación distinto del primero. Sin embargo, el tratamiento que se presenta en este primer apartado sobre la virtud de la justicia en Aristóteles, muestra

\footnotetext{
1 Este trabajo es una parte de la tesis que se realizó para alcanzar el grado de magister en el programa sobre "Realidad, conocimiento, acción" cursado en la Universidad de Navarra. Fue defendida en el año 2014. La tesis completa se encuentra publicada en Dadun (Depósito académico digital de la Universidad de Navarra).
} 
que para él se reconocen y distinguen dos ámbitos para la configuración de la justicia: la polis y la familia, sin que, al hablar de justicia, se deba atribuir necesariamente los calificativos de convencional y natural respectivamente a cada una de ellas.

Así pues, al comenzar el libro V Aristóteles deja claro que la justicia como virtud es una disposición de los hombres. Con esto me fijo en la primera característica de la justicia aristotélica, como es el hecho de que en la configuración de la justicia como virtud es central la participación de cada sujeto. Al Estagirita le interesa no solo la justicia en general, como principio estructurante de la vida en la polis, sino la virtud de la justicia, es decir, como disposición estable que configura el carácter de cada individuo. Esto manifiesta el fuerte sentido antropológico de la teoría aristotélica.

En efecto, en el texto de la Ética a Nicómaco se expresa:

Pues bien, vemos que todos están de acuerdo en llamar justicia a la disposición en virtud de la cual los hombres practican lo que es justo, obran justamente y quieren lo justo; y de la misma manera respecto de la injusticia: la disposición en virtud de la cual obran injustamente y quieren lo injusto. (EN 1129 a).

Desde el inicio se marca el tema de la voluntariedad, desarrollado en el capítulo octavo, noveno y parte del capítulo undécimo del mismo libro V. La presencia de esta disposición personal es decisiva al momento de reconocer la justicia como una virtud. Así, a lo largo del texto se explica que no es lo mismo lo justo, la acción justa y la justicia específicamente como virtud, lo mismo se puede decir de lo injusto, el acto injusto y la injusticia.

Aunque parezca redundante, desde mi punto de vista es necesario distinguir estas tres cosas, pues ya desde el inicio del libro V Aristóteles lo pone de manifiesto al decir "disposición en virtud de la cual los hombres practican lo que es justo, obran justamente y quieren lo justo". En este sentido solo es acto justo o injusto lo que se llega a ejecutar, pero no siempre una vez ejecutado se puede decir que se ha configurado una injusticia o se ha obrado con justicia ya que para esto último es necesaria la presencia de la voluntariedad. ${ }^{2}$

Si el daño se produce con deliberación previa, se obra injustamente, y el que obra injustamente cometiendo estas injusticias es ya injusto siempre que viole la proporción y la igualdad. Igualmente, un hombre será justo siempre que obre justamente en virtud de una elección, y obra justamente si sólo obra voluntariamente. (EN 1136 a)

\footnotetext{
2 Cfr. Aristóteles, Ética a Nicómaco, Madrid, Centro Estudios Constitucionales, 1970, V, 7, 1135a. En adelante EN.
} 
No es el momento para ahondar en lo que implica esta voluntariedad, pues este es un aspecto presente en toda virtud, pero aludir a ello nos permite introducir un segundo aspecto del tratamiento de la justicia aristotélica al que me referiré a continuación.

Y es que el tema de la justicia no se restringe solo a la voluntariedad, pues también se ha relacionado con el cumplimiento a la ley, aun cuando no esté presente la disposición voluntaria del sujeto; por ejemplo, cuando se cumple la ley por miedo al castigo, o por costumbre pues también en estos casos, donde la voluntariedad es imperfecta, el cumplimiento de la ley puede ir creando ciertos hábitos que, si bien no merecen el calificativo moral más alto, disponen de algún modo para la virtud.

Cabe observar que la justicia y la injusticia tienen varios sentidos, ${ }^{3}$ por esto antes de entrar en el tema de la justicia doméstica y política resaltaré otro de los puntos importantes en la teoría aristotélica donde se advierte la minuciosidad del tratamiento que hace el Estagirita.

Como se ha dicho, si bien la voluntariedad es definitoria para configurar la justicia como virtud, no es exclusiva, es decir, se puede hablar de justicia (o de injusticia) en otros sentidos. Así lo hace el autor; para explicarlo me centraré en el siguiente texto:

Parece que es injusto el trasgresor de la ley, y el codicioso, y el que no es equitativo; luego es evidente que será justo el que se conforma a la ley y el equitativo. Por consiguiente, lo justo es lo legal y lo equitativo, y lo injusto lo ilegal y lo no equitativo. [...] Como el trasgresor de la ley era injusto y el que se conformaba a ella justo, es evidente que todo lo legal es en cierto modo justo, pues lo establecido por la legislación es legal y de cada una de esas disposiciones decimos que es justa. (EN 1129 b)

Aquí se hace manifiesta una de las características más resaltantes en la teoría aristotélica, pues una de las definiciones de la justicia es la de lo justo como lo legal y del justo como aquel que se conforma a la ley. Cabe resaltar que el concepto que se maneja de legalidad no es el entendido en un sentido moderno o exclusivamente como derecho positivo. Más bien, como se percibirá más adelante, del mismo texto se puede deducir que en Aristóteles "lo legal" no es solo "ley escrita" sino que va más allá de esta. Entender esto ayuda a ver con claridad la estructura y los tipos de justicia que este autor presentará al hablar de la justicia política, sin que ninguna se aparte de la característica de la legalidad o sean contrapuestas.

Del texto, también se resalta la presencia de lo equitativo desarrollado en el capítulo décimo. A esto me referiré al tratar de la justicia natural, pero vale dejarlo mencionado en este momento por la importancia que tiene. Como se

3 Aristóteles, Ética a Nicómaco..., V, 1, 1129a.

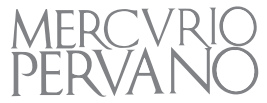


verá parecería que decir justo y equitativo suscitaría problemas, ${ }^{4}$ sin embargo esto no es así. Sobre ambos aspectos: legalidad y equidad, volveré más adelante.

Otra característica central del pensamiento aristotélico es que en su exposición la justicia es considerada como una virtud diferente a las demás virtudes. Por un lado, porque en su práctica se puede incluir el ejercicio de las demás virtudes. ${ }^{5}$

También es claro cómo deben definirse lo justo y lo injusto correspondientes: por lo general, la mayoría de las disposiciones legales están constituidas por prescripciones de la virtud total, porque la ley manda vivir de acuerdo con todas las virtudes y prohíbe que se viva en conformidad con todos los vicios. (EN 1130 b)

Y, por otro lado, es la virtud por excelencia porque se refiere al otro y no solo respecto al mismo sujeto, lo que significa que su ejercicio recae sobre el bien de uno mismo y de los demás.

Por lo mismo, también la justicia es, entre las virtudes, la única que parece consistir en el bien ajeno, porque se refiere a los otros. (EN 1130 a).

Existen más referencias en el texto a este carácter del otro, pero he seleccionado este porque en él se deja establecido literalmente que la justicia es la única de las virtudes a la que le corresponde este rasgo de la alteridad, del bien del otro.

Como se puede notar, el tratamiento aristotélico de la justicia presenta una estructura particular ya que independientemente de los tipos de justicia que se mencionan, sus contenidos no se contraponen, sino que más bien se adecúan a las distintas condiciones. Así pues, el Estagirita ha cubierto las situaciones que se pueden dar respecto a la justicia presentándola como un tema global y principal de la vida del hombre.

Todavía, sin embargo, se debe hacer referencia a otro punto importante en la justicia aristotélica. Si bien el Estagirita trata de la justicia natural y legal, en el texto se hace mención de la justicia total y además a un tipo de justicia particular. Esta última la divide a su vez en justicia distributiva y correctiva.

En este sentido, surge la pregunta: ¿Cómo se relacionan justicia especial (distributiva y correctiva), con la justicia legal, a la que ya nos hemos referido? Se relacionan como una virtud particular y una virtud total: pues la justicia legal puede mandar actos de aquellas virtudes. Sin embargo, es claro también que aquellas virtudes pueden ejercitarse asimismo en otros muchos casos no contemplados por la ley. Puede decirse, entonces, que entran dentro de la

\footnotetext{
${ }^{4}$ Ibid., V, 10, 1137b.

${ }^{5}$ Ibid, V, 1, 1129b. 
competencia de la "justicia natural", que, junto con la justicia legal, conforman lo que Aristóteles llama "justicia política".

Aristóteles dedica el capítulo tercero y cuarto al desarrollo de lo que él considera la justicia particular en sus dos vertientes como justicia distributiva o justicia correctiva, pues reconoce que existe un tipo de relación entre los particulares respecto de algo o de una cosa; independientemente de las relaciones que se establecen entre cada sujeto y su obediencia a lo dispuesto por la ley.

Ahora bien, incluso entre las relaciones de los particulares estas se dan de distinta manera, teniendo en cuenta las condiciones de cada uno de los sujetos y a la cosa. Cabe observar que, a diferencia de lo que ocurre con otras virtudes, la justicia se define por su referencia a un término medio que no reside en el sujeto sino en la cosa misma: a esto precisamente se llama derecho. Si bien el derecho en este sentido no se agota en lo prescrito por la ley. Como hemos dicho, hay muchas cosas que la ley positiva no prescribe y sin embargo son justas o injustas. La ley representa un cierto término medio, una medida objetiva respecto de la cual establecer la justicia o injusticia de ciertos actos.

Según dice el propio Aristóteles, la materia sobre la que versa la justicia especial es principalmente dinero y honores; otras veces se refiere genéricamente a aquellos bienes sobre los que versa el éxito o fracaso:

De la justicia parcial y lo justo de acuerdo con ella una especie es la que se practica en las disposiciones de honores, o dinero o cualquier otra cosa que se reparta entre los que tienen parte en el régimen (pues en estas distribuciones uno puede tener una parte igual o no igual a la de otro), y otra especie es la que regula o corrige los modos de trato. (EN 1130b)

La primera es la justicia distributiva, ${ }^{6}$ en la que lo justo es lo proporcional y lo injusto lo que va contra la proporción. ${ }^{7}$ En este tipo de justicia no se tiene en cuenta la igualdad en sentido estricto pues para dar a cada uno lo que le corresponde se tomará como punto de referencia el honor o méritos o los bienes que se reparten entre quienes forman parte de un régimen común. Esta referencia es importante, para entender por qué, en la Política, Aristóteles hace la justicia relativa al régimen: los criterios de justicia distributiva son conforme al régimen en el sentido de que dependen de la participación de cada cual en el régimen: si uno contribuye más al régimen en los términos prescritos por él, merece más, si contribuye menos, merece menos. La noción de "mérito" en todo caso es crucial. Así, lo justo como término medio requiere de por lo menos dos cosas y dos sujetos. ${ }^{8}$

\footnotetext{
6 Cfr. Luis García Soto, "La justicia en Aristóteles", en María José Agra Romero (y otros), En torno a la justicia: las aportaciones de Aristóteles, el pensamiento español de XVI, J.S. Mill, la fenomenología y Ralls, La Coruña, Eris, 1999, p. 32. Véase también Alasdair MACINTYRE, Justicia y racionalidad. Conceptos y contextos. Barcelona, Eunsa, 1994, p. 118.

7 Aristóteles, Ética a Nicómaco..., V, 3, 1131b.

${ }^{8}$ Ibid, V, 3, 1131a.
}

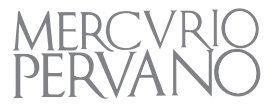


El segundo tipo de justicia particular es la correctiva que a diferencia de la anterior su ejercicio sí refleja la igualdad en sentido estricto pues en la aplicación de lo establecido por la ley se tendrá en cuenta el daño mismo independientemente de la persona que lo ha cometido o de los bienes que este posea. Es decir, trata como iguales al que comete la injustica y al que la sufre, al que perjudica y al perjudicado. ${ }^{9}$ Este es uno de los rasgos más fuertes que actualmente se mantienen y se procuran alcanzar en el campo del derecho: la igualdad de todos los ciudadanos ante la ley. Quiero enfatizar en este punto la aparición de la figura del juez como elemento central al momento de establecer la justicia, así el texto dice:

Por eso también siempre que hay discusión se recurre al juez, y el ir al juez es ir a la justicia, porque el juez quiere ser como una encarnación de la justicia. Por tanto, la justicia es un término medio, puesto que lo es el juez. El juez restablece la igualdad y es como si, de una línea cortada en partes desiguales, quitara a la mayor el trozo en que excede a la mitad y lo añadiera al segmento menor. Cuando el todo se divide entre dos, se dice que cada uno tiene lo suyo cuando han recibido partes iguales, y lo igual es el término medio entre lo mayor y lo menor según la proporción aritmética. (EN 1132a)

Después de haber explicado brevemente los rasgos característicos de la justicia aristotélica me centraré en los tipos de justicia y las diferencias que presenta Aristóteles según el sujeto se encuentre fuera o dentro de la polis. Es importante dejar claro que, en la visión aristotélica de la justicia, esta virtud, en su sentido más estricto, se ejerce en la polis, donde se trata a los otros como iguales. Respecto de esta noción estricta de justicia, la justicia que aparece en la familia tiene un carácter análogo, porque ahí los otros no son estrictamente iguales, y porque, además, no son totalmente otros, sino, en cierta medida, parte de uno mismo.

Pero antes de analizar este punto más derechamente, merece la pena referirse brevemente al modo en que Aristóteles habla de la reciprocidad como un tipo de justicia, distinta en un sentido de la justicia política aunque no totalmente separada ni contrapuesta de ella. En este sentido, si bien puede configurarse la reciprocidad entre los miembros de la polis -e incluso entre los amigos y en la familia- Aristóteles dice que el lugar propio de la reciprocidad es el de las relaciones de intercambio.

De este modo, si bien Aristóteles menciona la reciprocidad y le dedica un capítulo entero, no representa para él lo fundamental al momento de establecer el origen de la justicia, pues deja expresado que lo que a él le interesa no es la justicia sin más sino la justicia política. ${ }^{10}$

\footnotetext{
${ }_{9}$ Ibid, V, 3, 1131b.

${ }^{10} \mathrm{Ibid}, \mathrm{V}, 6,1134 \mathrm{a}$.
} 
Hemos dicho antes la relación que existe entre la reciprocidad y la justicia; pero no debemos olvidar que lo que buscamos no es sólo la justicia sin más, sino la justicia política. (EN 1134 b)

En síntesis, en las relaciones de intercambio que surgen entre los sujetos particulares lo que se debe aplicar es la justicia entendida como reciprocidad para alcanzar la igualdad, solo así se cumple con la característica de la justicia de dar a cada uno lo suyo. Es importante destacar que, aunque en estos intercambios se deja cierta libertad a los sujetos que participan de ellos, la existencia de la moneda como una convención y como lo que permite igualar el valor de lo que se intercambia, coloca a este tipo de justicia en relación más directa y cercana a la justicia política de lo que estará la justicia doméstica.

Concluyo esta primera parte haciendo mención a la división de la justicia que se viene mencionando desde el inicio de este apartado. El capítulo séptimo del libro V de la Ética a Nicómaco inicia con la presentación de la justicia política como aquella que se divide en natural y legal. Pero antes al finalizar el capítulo sexto del mismo texto, el Estagirita deja esbozado otro tipo de justicia. Esta es la justicia doméstica como aquella distinta de la política y que por lo tanto no tiene lugar en la polis sino en un ámbito diferente que depende de las relaciones existentes dentro de la familia, a saber, las de marido-mujer, padre-hijo y amo-esclavo.

Es muy interesante que para él la justicia como natural sea entendida en el ámbito de la polis y no en el de familia como podría erróneamente interpretarse. Empezaré por la explicación de la justicia política, pues es en ella donde se presentan propiamente las características de la justica, siendo que solo de manera análoga se dan en la justicia doméstica. A explicar esto dedico los siguientes apartados.

\section{Justicia política}

El capítulo sexto y séptimo de la Ética a Nicómaco se dedican exclusivamente a la justicia política -como natural, como legal- y en cierto sentido al delimitar esta justicia refiere a la justicia doméstica.

Aunque precisamente estos pasajes han sido objeto de numerosos comentarios, aquí los traemos a colación con una intención muy precisa: delimitar los ámbitos de justicia y resaltar el papel que cumple esta virtud en los distintos tipos de relaciones que se establecen en la vida de los hombres.

De lo expresado hasta el momento, se sigue que para Aristóteles la virtud de la justicia tiene un papel central en la configuración de la vida en sociedad -y es esta justicia la que busca estudiar- es decir en lo que él llama polis. Así reconoce un tipo de justicia exclusivamente política, dentro de la que hará también una división entre lo que denomina justicia natural y justicia legal. En un primer momento parecería que al decir "política" se hará referencia solo a

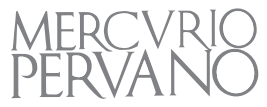


la justicia que se rige concretamente por la ley escrita, o lo que ahora se conoce como ley positiva, pero no es así.

De manera global y antes de empezar a explicar lo referente a la justicia natural y legal, Aristóteles dice que la justicia política se da entre personas libres e iguales que participan de una vida en común. ${ }^{11}$ De este modo se circunscribe, primero, que la justicia política presenta un espacio definido de realización entre determinados tipos de sujetos -libres e iguales- y no cualquier persona. Segundo, debe haber vida en común que como se sabe en Aristóteles significa no solo vivir en una determinada ciudad sino además con miras a un fin común, de esto que también la justicia tenga que ver con la producción y preservación de la felicidad, ${ }^{12}$ en lo que no me voy a detener. Tercero, entre aquellos sujetos que no sean libres e iguales no cabe este tipo de justicia, sino solo justicia en cierto sentido y por analogía ${ }^{13}$. Decir esto último no es redundante pues con ello Aristóteles salva aquellos espacios donde si bien no existe lo político hay lugar para cierto sentido de justicia; es decir: la justicia como virtud para Aristóteles no existe solo como cimiento o para regular la vida de la polis, sino que entra en juego, aunque sea en sentido análogo, en toda clase de relaciones.

Se han destacado ya las condiciones que Aristóteles establece para que pueda darse la justicia política. Dado que, al exponer estos puntos, relativos a la justicia política, Aristóteles no ha introducido todavía la división interna de la justicia política en dos aspectos: natural y legal, se entiende que todos los puntos se aplican a ambas. Con esto en mente, tiene interés leer lo que dice sobre la justicia política:

Hay justicia, en efecto, para aquéllos cuyas relaciones están reguladas por una ley, y hay ley entre quienes se da la injusticia porque la justicia del juicio es el discernimiento entre lo justo y lo injusto. Donde hay injusticia se cometen acciones injustas (pero no siempre hay injusticia donde se cometen acciones injustas), y éstas consisten en atribuirse a uno mismo más de aquello que es bueno absolutamente hablando y menos de lo malo absolutamente hablando. Por eso no permitimos que nos mande un ser humano, sino la razón, porque el hombre hace eso en su propio interés, y se convierte en tirano. El gobernante es guardián de la justicia, y si de la justicia, también de la igualdad. (EN $1133 a-b)$

Del texto se podría concluir que Aristóteles dice que la justicia se da entre aquellas relaciones reguladas por una ley. La pregunta que surgiría es ¿se está refiriendo solamente a la ley de tipo escrito o se puede extender lo que el texto apunta a un tipo de justicia no escrita? Literalmente no dice nada más, sin embargo de todo lo estudiado hasta el momento me inclino por

${ }_{11}$ Ibid, V, 6, 1134a.
${ }^{12}$ Ibid, V , 1, 1129b.
${ }^{13}$ Ibid, V, 6, 1134a. 
una interpretación más bien incluyente de ambos tipos de justicia natural y legal. ${ }^{14}$

Por un lado, si bien de la lectura del libro V, se puede notar que Aristóteles da mucho más énfasis a lo justo legal, también se hace referencia a la lo justo como lo igual o equitativo, que se estudiará más adelante y en este sentido a lo justo natural, que no está siempre necesariamente reflejado en una ley escrita. Además, como ya se ha apuntado, otro aspecto a favor es que para Aristóteles hablar de legalidad no es estrictamente referirse a la ley escrita, sino también a un tipo de legalidad que va más allá, en cuanto que se está refiriendo a lo que sucede en las diversas situaciones de lo justo o injusto, sin que sea exclusivo de la ley escrita regular todas las situaciones; es más en el capítulo décimo del libro $\mathrm{V}$, reconoce la existencia de lo equitativo que siendo justo, lo es no en el sentido de la ley sino como rectificación de la justicia legal. ${ }^{15}$

Luego, en el mismo texto se ha mencionado la figura del gobernante, independientemente de que se trate una justicia de tipo natural o legal. Por lo tanto, sin negar la prioridad y hasta necesidad de una ley escrita, puede configurarse lo justo o injusto al margen de la existencia de una ley escrita.

Pues bien, situadas la justicia natural y legal dentro de la polis, es momento de estudiar la razón o razones por las que el Estagirita ha hecho esta distinción.

\section{Justicia natural}

Aunque esta justicia pertenece al ámbito político, Aristóteles no ha dedicado mucho texto respecto a ella, sin embargo. sí deja establecido que la principal diferencia entre esta justicia natural y la legal es que la primera tiene en todas partes la misma fuerza, lo cual no significa que sea inmutable, por lo menos no para los hombres. Así Aristóteles dice que toda justicia es variable. ${ }^{16}$ Vale recordar que toda justicia política, en cualquiera de sus manifestaciones, tiene inherente un sentido de legalidad, en cuanto que con ello se refleja lo justo.

En este sentido, si bien la justicia natural aristotélica no presenta una estructura determinada, es importante destacar que ella misma emana de las relaciones entre los sujetos directamente relacionadas con la propia naturaleza humana y no en virtud de lo convencional en un sentido positivo. Así pues, se podría incluir lo que los estoicos y los romanos posteriormente calificaron de

\footnotetext{
${ }_{14}$ Con esto remito, básicamente, a lo expresado por Maritain sobre la ley no escrita: "La ley natural no es una ley escrita. Los hombres la conocen con mayor o menor dificultad, y en grados diversos, y con riesgo de error en ella como en otras cosas [...] La ley natural es una ley no escrita. El conocimiento que de ella tiene el hombre ha crecido poco a poco con los progresos de la conciencia moral". Ver Jacques MARITAIN, Los derechos del hombre y la ley natural, Buenos Aires, Editorial Dédalo, 1961, pp. 102-103.

15 ARISTÓteles, Ética a Nicómaco..., V, 10, 1137b.

${ }^{16} \mathrm{Ibid}, \mathrm{V}, \mathrm{7}, 1134 \mathrm{~b}$.
} 
comportamientos conforme a la naturaleza como lo que entra más ampliamente dentro del capítulo de "derecho consuetudinario", costumbres que se imponen por sí mismas en la vida social sin necesidad de una prescripción legal.

Al reconocer la existencia de una justicia de este tipo el Estagirita es consciente que hay situaciones que pueden escapar al mismo gobernante y a la comunidad, sin que esto signifique que no puede darse la justicia sin la presencia de un contenido estrictamente legal. Esta es una idea que modernamente se ha expresado en el Derecho a través de los principios generales del Derecho, los cuales pueden alegarse independientemente del sitio donde uno se encuentre.

Ahora, si bien Aristóteles no habla de un Derecho Natural, sí podemos, en cierta manera, asimilar este tipo de justicia a lo que hoy conocemos con tal nombre, pues son preceptos que sin necesidad de estar reconocidos por el derecho positivo y al emanar de la propia condición humana deben ser atendidos por quien administra la justicia. No es mi fin explicar esto a detalle; no obstante, vale manifestar aquí que es una imposibilidad que todo sea regulado mediante la ley, siempre habrá situaciones que queden fuera, además de que la misma ley humana positiva puede presentar fallos.

De este modo, y en razón a lo mencionado, es oportuno hacer una breve referencia a la equidad ${ }^{17}$ y lo equitativo, pues como se expresa la equidad sin ser ajena a lo justo, es de alguna manera mejor que lo justo, entendida como aquella que rectifica la justicia legal cuando existe algún tipo de error u omisión, el cual no se atribuye a la ley en sí misma o al legislador, sino a la misma índole de las cosas y que debe ser corregido. ${ }^{18}$

Si bien no se hace una identificación de la epiqueya con la justicia natural, sí se puede interpretar que ambas comparten su existencia (no contrapuesta) con la justicia entendida como legal. Digo esto porque Aristóteles señala la epiqueya como aquella que rectifica, mas no la que se contrapone o elimina la justicia legal. ${ }^{19}$ En este sentido, la justicia legal viene a apoyarse en la epiqueya.

lo equitativo, si bien es mejor que una especie de justicia, es justo, y no es mejor que lo justo como si se tratara de otro género. Lo mismo es, por tanto, justo y equitativo, y siendo ambos buenos, es mejor lo equitativo. Lo que ocasiona la dificultad es que lo equitativo es justo, pero no en el sentido de la ley, sino como una rectificación de la justicia legal. La causa de ello es que toda la ley es universal, y hay cosas que no se pueden tratar rectamente de un modo universal". (EN 1137b)

\footnotetext{
17 Cfr. Eduardo Garcia Máynes, Doctrina aristotélica de la justicia, México, Instituto de Investigaciones Filosóficas, 1973, pp. 141-147.

${ }_{18}$ Cfr. Aristóteles, Ética a Nicómaco..., V, 10, 1137b.

${ }^{19}$ Cfr. Ana Marta GonZÁLez, "Dos visiones del derecho. La epiqueya en Aristóteles y Kant", en Persona y Derecho, 46 (2002), p. 244.
} 


\section{Justicia legal}

Si la justicia natural es la que presenta la misma fuerza en todas partes, resulta fácil deducir que con la justicia legal no sucede lo mismo, por el contrario, este tipo de justicia es de alguna manera la que se configura según determinadas leyes que obedecen a los distintos tipos de gobierno en las diferentes comunidades -reflejados en una ley escrita específica en cada lugarde acuerdo a sus condiciones y necesidades.

Parecería que este tipo de justicia tiene mayor fuerza de coerción que la natural y es lo propio si se habla estrictamente de la polis, porque una vez establecida ya no da lo mismo que sea de una $u$ otra manera sino que debe obedecerse el precepto que la ley establece y que es fruto de las convenciones humanas. ${ }^{20}$

La justicia fundada en la convención y en la utilidad es semejante a las medidas: las medidas del vino y del trigo no son iguales en todas partes, sino mayores donde se compra y menores donde se vende. De la misma manera las cosas que no son justas por naturaleza sino por convenio humano no son las mismas en todas partes, puesto que no lo son tampoco los regímenes políticos, si bien sólo uno es por naturaleza el mejor en todas partes. (EN 1135a)

A pesar, de que Aristóteles ha reconocido expresamente dos tipos de justicia en la polis, esto no quiere decir que una sea más que otra o sean excluyentes, sino más bien que existe una aplicación de la justicia legal, en este caso del cumplimiento y obediencia a lo que dice la ley escrita que debe mirarse primero. Esta idea viene, además, justificada porque si bien el autor se refiere a la polis en general existen distintos tipos de gobierno, en los cuales se establece una justicia legal de tipo específico, acorde a cada comunidad.

Pero es fundamental tener en cuenta que la justicia legal debe subordinarse al bien común, lo cual es de justicia natural. Cuestión distinta es que la articulación del bien común, en la práctica, precise de leyes positivas -como se dijo- por lo cual esto depende de las convenciones o acuerdos a los que lleguen cada comunidad al establecer sus leyes positivas -justicia legal-, con base en la justicia natural.

Además, si bien la justicia no se reduce a la mera obediencia a la ley, sí es imprescindible que el gobernador procure dicha obediencia, pues aunque no se llegue a configurar la justicia como una disposición voluntaria del sujeto o en cada uno de los ciudadanos, si se cumple lo que la ley prescribe hay presencia de lo justo, incluso de actos justos, aunque no se hable de una justicia como virtud o disposición; en el mismo sentido, si es que se incumple la ley se

${ }^{20}$ ARIstóteles, Ética a Nicómaco..., V 7, 1134 b.

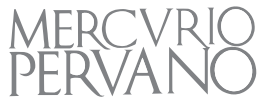


puede configurar lo injusto o actos injustos. Entonces, si bien no es necesaria la presencia del elemento volitivo en la actuación del ciudadano -lo preferible es que sí se dé- sí hay lugar para la justicia entendida como lo legal, esto significa como obediencia a la ley.

Esimportante recordarque para Aristóteles esta obediencia y cumplimiento de la ley tiene entre sus objetivos convertirse -si es que no está presente- en un futuro en la disposición como una virtud en el sujeto.

\section{Justicia doméstica}

Al inicio de este capítulo he dejado claro que el texto central para enfocar la justicia aristotélica es el libro $\mathrm{V}$ de la Ética a Nicómaco, asimismo que este tema no es exclusivo de este libro sino que también es explicado a lo largo de la Política ${ }^{21}$ y parte de la Retórica. Pues bien, cuando Aristóteles trata sobre la justicia doméstica en el libro $\mathrm{V}$ hace solo dos referencias a ella en el capítulo sexto -para distinguirla de la justicia política- y al finalizar el capítulo undécimo.

De estas lecturas se extrae que la justicia doméstica, no siendo la justicia más importante para Aristóteles, presenta una estructura e incluso una jerarquización entre las relaciones que pueden surgir fuera de la polis en el ámbito familiar donde el referente central es el varón, sea como marido, padre o amo. Para el interés de este trabajo basta con las referencias que se hacen en el libro V.

Si bien Aristóteles deja mencionado el tipo de justicia doméstica en el capítulo sexto, no ofrece mayor desarrollo de esta en este libro. Sin embargo, su tratamiento se extiende en el libro VIII de la Ética a Nicómaco, siendo su objeto central la amistad y a través de esta el autor vuelve a presentar -además- el tema de la justicia.

La vida humana no se desempeña de manera inmediata en la polis, sino que primero se desarrolla en el seno de una familia: entre padres y hermanos; y solo por mediación de la familia, se desempeña en la polis, de la que se llega a ser miembro de pleno derecho solo transcurrido cierto tiempo.

La existencia de la justicia doméstica se pone de manifiesto cuando Aristóteles define entre quienes puede darse la justicia política, es decir, entre personas libres e iguales, de modo que entre los que no están en estas condiciones no puede haber justicia política de los unos respecto de los otros sino solo en cierto sentido y por analogía. ${ }^{22}$ Para Aristóteles son libres e iguales aquellos varones que forman parte y participan de la polis. Entonces, ¿qué sucede con quienes se encuentran fuera de ella (a saber, la mujer, el niño o los esclavos)

${ }^{21}$ Específicamente en el Libro I de la Política de Aristóteles. Madrid, Centro de Estudios Constitucionales, 1997.

22 Aristóteles, Ética a Nicómaco..., V, 6, 1134a.

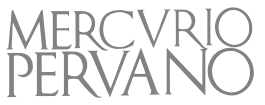


cuando entran en relación con quienes sí son reconocidos como ciudadanos? ¿Hay lugar en las relaciones familiares para lo justo-injusto, acciones justasinjustas, o para la justicia o injusticia? Aristóteles reconoce que sí.

En el siguiente texto, Aristóteles muestra cómo de los tipos de relaciones se puede deducir que existe un tipo de justicia semejante, pero no entendida como política sino distinta de ella.

La justicia del amo y la del padre no es la misma que la de los gobernantes, aunque es semejante. En efecto, no hay injusticia, de un modo absoluto, respecto de lo propio, y la propiedad, y el hijo, hasta que llega a una edad determinada y se hace independiente, son como partes de uno mismo, $y$, nadie se perjudica a sí mismo deliberadamente. Por eso no hay injusticia para con uno mismo y, por tanto, tampoco hay injusticia ni justicia política en esas relaciones: quedamos, en efecto, en que esa clase de justicia era según ley, y en que tienen ley de modo natural aquellos que son iguales en el mando y en la obediencia. Por esta razón la justicia se refiere más a la mujer que a los hijos o la propiedad; pero se trata en este caso de la justicia doméstica, que es también distinta de la política. (EN 1134 b)

En definitiva, Aristóteles es claro al distinguir este tipo de justicia de cualquier otra. Refiere expresamente a la relación del amo-esclavo, del padrehijo, y al finalizar a la justicia propia de la relación entre el marido y la mujer. No detallaré cada una de ellas, pero es muy interesante que Aristóteles, cuando en el libro VIII entra un poco más a fondo en ellas, lo hace (como ya se anotó) con directa referencia a la amistad. Esto llama la atención porque para él pueden existir ambas virtudes -amistad y justicia- al mismo tiempo no solo en la familia sino también en la polis. ${ }^{23}$ Es diferente al tratamiento que le da David Hume, pues este parentesco no se hace manifiesto, mucho menos en la familia, donde solo hay lugar para la primera de ellas; tal vez porque para Hume la justicia, debido al enfoque que adopta, no admite un tratamiento análogo, como sí ocurre en cambio con Aristóteles. ${ }^{24}$

En síntesis, la teoría aristotélica de la justicia tiene un profundo sentido antropológico, por un lado, debido a los distintos espacios donde se puede dar su configuración (relaciones familiares y políticas, además del reconocimiento de las relaciones de intercambio) y, por otro, por ese carácter de la justicia como

23 Cfr. Ana Marta GonzÁlez, La articulación ética de la vida social, Granada, Comares, 2016, pp. 14-16.

${ }_{24}$ Para mayor detalle sobre el tema de las virtudes que se dan dentro de la familia en el desarrollo de la filosofía humeana véase "La oposición de pasiones y su superación en el trato social según Hume: familia, castidad y cortesía" en Ana Marta GonZÁLez, Sociedad Civil y normatividad: la teoría social de David Hume, Madrid, Dykinson, 2013. Así también puede verse Juan Andrés Mercado, Entre el interés y la benevolencia. La ética de David Hume, Berna, Peter Lang, 2013.

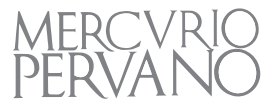


una disposición voluntaria y personal que puede llegar a darse en la perfección de cada sujeto. Pero lo que más quiero resaltar es justamente el valor que da Aristóteles a la justicia en la polis y en sentido análogo a la familia. así como su sorprendente división de la justicia política en natural y legal, diferente de la justicia doméstica.

Sin duda, no podemos negar que la manera en que Aristóteles realiza el análisis sobre la virtud de la justicia presenta una riqueza indiscutible, que hasta la fecha es modelo y paradigma no solo en relación con el derecho sino con otras ciencias como la ética que los modernos muchas veces pretenden separar.

\section{Conclusiones}

Primero, Aristóteles entiende principalmente la virtud de la justicia como una disposición en el sujeto, es decir que para su configuración como virtud es necesaria la presencia de la voluntariedad al momento de la ejecución de los actos justos, ya se trate de actos de justicia distributiva o de justicia correctiva, en ambos casos actos de la justicia como virtud especial, si bien, como se ha indicado, este no es el único sentido que el Estagirita otorga a la justicia, pues también habla de lo justo como obediencia a la ley.

Segundo, aunque siempre que hablemos de virtud sea necesaria afirmar la voluntariedad con la que el sujeto ejerce los actos correspondientes (ya sea los de la justicia especial, ya sea los de la justicia legal), el objeto de la justicia puede definirse, en ambos casos también, con una cierta independencia: esto es lo propio de la virtud de la justicia, a diferencia de otras virtudes: que el término medio que permite constituirla no se define por referencia a las disposiciones del sujeto, sino por referencia a relaciones objetivas (ya sean las que vinculan a sujetos particulares, ya sean las que vinculan a los sujetos particulares con la ley). Con otras palabras: uno puede hacer lo justo sin ser interiormente justo; por ejemplo, movido por temor, o por otras causas.

Tercero, Aristóteles centra su estudio en la justicia política. Esta parece constituir el sentido propio y primero de justicia; mientras que lo que él denomina "justicia doméstica" parece tener un sentido análogo y derivado. Según esto, el lugar propio de la justicia es la polis, conformada por aquellos hombres libres e iguales. Al mismo tiempo, Aristóteles deja claro que la justicia política no se limita a la justicia legal: también incluye lo que él llama "justicia natural".

Cuarto, en el marco de la justicia política entendemos esa "cierta igualdad" en la que consisten la justicia especial, ya sea la correctiva o la distributiva y también el vicio que, según Aristóteles, se opone directamente a esa virtud: la codicia. Lo típico del codicioso, en efecto, es querer más de 
los bienes que en justicia le corresponden y, derivadamente, querer menos de los males que en justicia le corresponden.

Quinto, lo más importante de esta virtud, en lo que Aristóteles hace consistir su condición de "virtud perfecta", es que hace referencia a otro. La insistencia de Aristóteles en que la justicia hace referencia "a otro", da a entender que puede haber formas más o menos justas, y no solo más o menos afectuosas, de tratar también a los de la propia casa. 